\title{
Effect of Mobility on (I-V) Characteristics of Gaas MESFET
}

\author{
M Azizi, C Azizi \\ Faculty of exact sciences and natural and life sciences, Active Devices and Materials Laboratory, \\ Larbi Ben M’Hidi University, Oum El Bouaghi, Algéria
}

\begin{tabular}{|c|c|}
\hline Article Info & ABSTRACT \\
\hline Article history: & \multirow{6}{*}{$\begin{array}{l}\text { We present in this paper an analytical model of the current-voltage (I-V) } \\
\text { characteristics for submicron GaAs MESFET transistors. This model takes } \\
\text { into account the analysis of the charge distribution in the active region and } \\
\text { incorporate a field depended electron mobility, velocity saturation and charge } \\
\text { build-up in the channel. We propose in this frame work an algorithm of } \\
\text { simulation based on mathematical expressions obtained previously. We } \\
\text { propose a new mobility model describing the electric field-dependent. The } \\
\text { predictions of the simulator are compared with the experimental data [1] and } \\
\text { have been shown to be good. }\end{array}$} \\
\hline Received Jul 9, 2016 & \\
\hline Revised Oct 28, 2016 & \\
\hline Accepted Sep 11, 2017 & \\
\hline Keyword: & \\
\hline GaAs & \\
\hline
\end{tabular}

MESFET

Mobility

Modeling

Copyright $\odot 2017$ Institute of Advanced Engineering and Science. All rights reserved.

\section{Corresponding Author:}

Azizi Mounir,

Faculty of exact sciences and natural and life sciences,

Active Devices and Materials Laboratory,

Larbi Ben M'Hidi university,

Oum El Bouaghi, Algéria.

Email: mounir.perso@gmail.com

\section{INTRODUCTION}

The GaAs MESFET are attractive devices for the use in microwave applications because of their relatively simple processing and their high-speed and low noise performance [2]. The current-voltage depends on the law of carrier mobility as a function of electric field. The choice of a mobility law is very important for a proper description of physical phenomena in submicron-gate MESFET. The principal object in this paper is to propose a physical and analytical model of the characteristics current voltage of these devices with a new electron mobility law.

First, we calculate the potential field in the depletion layer S.C.Z due to the electrical charge formed under the gate which can be obtained by resolving the Poisson's equation by the conventional approximation. Then we determine the drain current Id, the characteristic I-V obtained by this model, using anew expression of the electrons velocity $\mathrm{v}(\mathrm{E})$ for different dimensions of channel. This model takes into account in the hand the specifics physical phenomena in devices and on the other hand simplicity of mathematical expressions. We have elaborated software of simulation that will enable us to solve the system of differential equations and totrace the various series of curves.

\section{CALCULATION OF THE POTENTIAL AND THE DRAIN CURRENT IN THE CHANNEL AND THE ELECTRICAL FIELD}

To calculate the potential and the electric field under the gate, the channel is divided into two principal regions Figure 1.

a. The first region (1) the gate directly is controlled by the gate.

b. The second region (2) outwards of the first region known as region not controlled by the gate. 


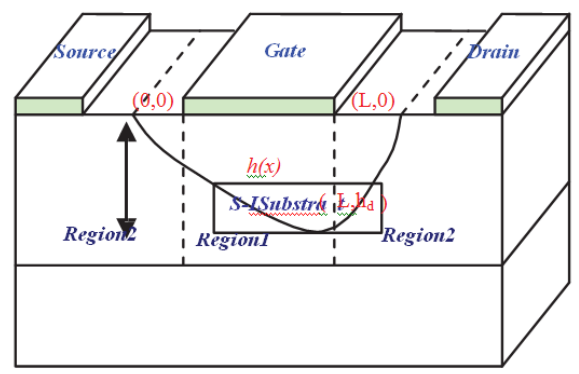

Figure 1. Depletion Regions: (1) Controlled by the gate, (2) Not Controlled by the gate

The electric potential due to the electrical charge formed under the gate can given by [2]:

$$
V_{q}(x, y)=\int_{0}^{y} \frac{e N d(x, y)}{\varepsilon} y d y+y \int_{y}^{h(x)} \frac{e N d(x, y)}{\varepsilon} d y+V b i-V g
$$

$\operatorname{Nd}(x, y)=N d(y)-n(x, y)$, with $\operatorname{Nd}(y)$ is the density of the donors which can be varied with $y$, and $\mathrm{n}(\mathrm{x}, \mathrm{y})$ the density of the free electrons in the depletion layer. Vbi is the built in potential of Schottky barrier gate and $\varepsilon$ is the permittivity.

It should be noted that the approximations in (1) is based on the fact that the depletion layer thickness under the gate $\mathrm{h}(\mathrm{x})$ is a slowly varying function in the channel and is giving by:

$$
\mathrm{h}(\mathrm{x})=\left[\frac{2 \varepsilon(\mathrm{Vbi}-\mathrm{V})}{\mathrm{qNd}}\right]^{1 / 2}
$$

The channel potential is obtained by integration limits with $\mathrm{y}=\mathrm{h}(\mathrm{x})$

$$
\mathrm{V}(\mathrm{y})=\frac{\mathrm{qNd}}{\varepsilon}\left[\mathrm{hy}-\frac{\mathrm{y}^{2}}{2}\right]
$$

The equation of the potential takes a maximum of values in diffusion potential $\mathrm{Vbi}(\mathrm{y}=\mathrm{h})$.

$$
V_{b}=V(y=h)-V(y=0)
$$

The dimensional potential of the channel under the gate is given as follows:

$$
\mathrm{V}(\mathrm{x})=\frac{\mathrm{qNdh}^{2}(\mathrm{x})}{2 \varepsilon}+\mathrm{V}_{\mathrm{g}}-\mathrm{V}_{\mathrm{bi}}
$$

Calculation of drain current in the channel:

To calculate the drain current expression as a function of the drain voltage, we must make some approximations [3]:

a. One neglects the current flow in the y-direction. This approximation is valid for the components with the short length gate.

b. An abrupt junction Schottky barrier.

c. A channel of uniform doping $\mathrm{Nd}(\mathrm{x}, \mathrm{y})=\mathrm{Nd}, \mathrm{Nd}$ is constant.

d. Neglecting edge effects, the overflow area depopulated on the sides of the gate

The density of the current is given by:

$$
\mathrm{J}_{\mathrm{x}}=\sigma(\mathrm{x}, \mathrm{y}, \mathrm{z}) \cdot \mathrm{E}_{\mathrm{x}}
$$

With $\sigma(\mathrm{x}, \mathrm{y})=\rho(\mathrm{y}) \mu_{\mathrm{n}}\left(\mathrm{E}_{\mathrm{x}}\right)$

$$
J_{x}=q N_{d} \mu_{n} E_{x}=-q \mu_{n} N_{d} \frac{d V(x)}{d x}
$$

$\mu_{n}\left(E_{x}\right)$ is the electron mobility which depends of the electric field. 
The drain current Id counted positively in the sense drain source is obtained by integrating across the $\mathrm{J}_{\mathrm{x}}$-conductor section of the channel:

$$
\begin{aligned}
& I_{d}=-\int_{0}^{Z} \int_{h(x)}^{a} J_{x} d y d z=-Z \int_{h(x)}^{a} J_{x} d y \\
& v_{x}\left(E_{x}\right)=\mu_{n} E_{x}(x)
\end{aligned}
$$

The calculations made above, unaware of the contribution depletion layer located below the free surface in the potential, we put:

$$
\mathrm{I}_{\mathrm{p}}=\frac{(\mathrm{qN})^{2} \mu_{\mathrm{n}} \mathrm{Za}^{3}}{2 \mathrm{~L} \varepsilon}
$$

q: electron charge.

$\mathrm{N}_{\mathrm{d}}$ : carrier density in the channel.

a: channel thickness.

$\mathrm{L}$ : intrinsic channel length (controlled by the gate).

$$
\begin{aligned}
& \mathrm{V}_{\mathrm{p}}=\mathrm{q} \frac{\mathrm{N}_{\mathrm{d}} \mathrm{a}^{2}}{2 \varepsilon}=\mathrm{V}_{\mathrm{bi}}-\mathrm{V}_{\mathrm{g}} \\
& \mathrm{a}=\left[\frac{2 \varepsilon}{\mathrm{qN}}\left(\mathrm{V}_{\mathrm{bi}}-\mathrm{V}_{\mathrm{g}}\right)\right]^{1 / 2} \\
& \frac{\mathrm{h}(\mathrm{x})}{\mathrm{a}}=\left[\frac{\mathrm{V}_{\mathrm{bi}}+\mathrm{V}(\mathrm{x})-\mathrm{V}_{\mathrm{g}}}{\mathrm{V}_{\mathrm{bi}}-\mathrm{V}_{\mathrm{g}}}\right]
\end{aligned}
$$

Then the final expression of the current Id [4] is given by:

$$
I_{d}\left(V_{d}, V_{g}\right)=I_{p}\left[\frac{v_{d}}{V_{p}}-\frac{2}{3}\left[\left(\frac{v_{d}+V_{b i}-V_{g}}{V_{p}}\right)^{3 / 2}-\left(\frac{v_{b i}-V_{g}}{v_{p}}\right)^{3 / 2}\right]\right]
$$

\section{EFFECT OF VARIABLE MOBILITY}

The dependence of the electron drift velocity on the applied field remains one of the most important relations required in the numerical simulations of $\mathrm{GaAs}$ devices.

For low electric field the carrier mobility remains constant and varies from one material to another, and the carrier velocity is directly proportional to the electric field. It is defined by the equation [5].

$$
V(E)=\mu_{0} E
$$

$\mu_{0}$ : the mobility of electrons at low electric field.

However, when the applied electric field becomes important, the electron transfer intervals induced in the GaAs a decrease of the carrier velocity and leads to strong negative differential mobility [6]. This decrease results in a non-linear variation of the drift velocity of the carriers. Therefore, several approximate analytical expressions have been proposed for this function [7].

For our study, we have tested two mobility laws for the reason that they have good approximations comparing to the experimental data. When $E<E_{0}$ which corresponds to the critical field, the two expressions are given by:

First expression [8], [9]:

$$
\mu_{2}(E)=\frac{\mu_{0}+v_{s}\left(\frac{E^{3}}{E_{c}}\right)}{1+\left(\frac{E}{E_{c}}\right)^{4}}
$$

First expression [10]: 


$$
\begin{aligned}
& \mu_{1}(E)=\frac{v_{S}}{E} \tanh \left(\frac{\mu_{0} E}{v_{S}}\right) \\
& E_{C}=v_{S} / \mu_{0}[11] ; \\
& E_{0}=\frac{1}{2}\left[E_{S}+\left(E_{S}{ }^{2}-4 E_{C}{ }^{2}\right)^{1 / 2}\right]
\end{aligned}
$$

$\mathrm{E}_{\mathrm{c}}$ : the critical field at which the velocity in the linear regime is equal to the saturation value.

$\mathrm{E}_{\mathrm{s}}$ : the threshold field, corresponding to the maximum value of the electrons velocity, which can be calculated from the following relationship:

$$
\left.\frac{d V}{d E}\right|_{E=E_{S}}=0
$$

In this section, we describe the introduction of a new empirical apparent velocity field relationship suitable for GaAs MESFET's with different gate length. We propose a new model which is a very simple expression and easy to use in the different current-voltage analytical models.

The new expression is a variation with twosegments approach of the velocity versus electric field. A linear variation of the carrier velocity, with the increasing of the applied electric field. then saturation at a large drain voltage [12].

The proposed expression of the velocity is given by:

$$
v_{n}(E)=\mu_{n}(E) E=\frac{\mu_{0} E}{\left(1+\left(\frac{E}{E_{C}}\right)^{n+1}\right)^{1 / n}}
$$

So, the expression of the mobility is as follows:

$$
\mu_{n}=\frac{\mu_{0}}{\left(1+\left(\frac{E}{E_{c}}\right)^{n+1}\right)^{1 / n}}
$$

$n$ may be taken equal to 1 or 2 for a best fitting of the Current -Voltage characteristics and to be as close as possible to the two segments approach.

The general equation of the current using $\mu_{n}$ becomes:

$$
I_{d}=I_{p} A\left[\frac{V_{d s}-\left(R_{s}+R_{d}\right) I_{d}}{V_{p}}-\frac{2}{3}\left(\frac{V_{d s}+V_{b i}-V_{g s}+R_{S} I_{d}}{V_{p}}\right)^{3 / 2}+\frac{2}{3}\left(\frac{V_{b i}-V_{g s}+R_{S} I_{d}}{V_{p}}\right)^{3 / 2}\right]
$$

with

$$
A=\frac{1}{\left\{1+\left(\left[V_{d s}-\left(R_{S}+R_{d}\right)\right] / L E_{c}\right)^{n+1}\right\}^{1 / n}}
$$

$R_{S}$ is the Source series resistance and $R_{d}$ is the drain series resistance.

\section{RESULTS AND DISCUSSIONS}

The numerical calculation of the current of drain according to the biasing calls upon the expressions (8), (9), (10) established previously. The study was carried out on a submicron gate GaAs MESFET's which the physical and geometrical parameters are gathered in the Table 1.

Table 1. Parameter of the GAT1

\begin{tabular}{cccccccc}
\hline Transistor & $\begin{array}{c}\mathrm{L} \\
(\square \mathrm{m})\end{array}$ & $\begin{array}{c}\mathrm{A} \\
(\mathrm{nm})\end{array}$ & $\begin{array}{c}\mathrm{Z} \\
(\square \mathrm{m})\end{array}$ & $\begin{array}{c}\text { Vbi } \\
(\mathrm{V})\end{array}$ & $\begin{array}{c}\mathrm{N}_{\mathrm{d}} \\
\left(\mathrm{cm}^{-3}\right)\end{array}$ & $\begin{array}{c}\square_{0} \\
\left(\mathrm{~m}^{2} \mathrm{~V}^{-1} \mathrm{~s}^{-1}\right)\end{array}$ & $\begin{array}{c}\mathrm{v}_{\mathrm{s}} \\
\left(\mathrm{ms}^{-1}\right)\end{array}$ \\
\hline GAT1 & 0.28 & 90 & 100 & 0.8 & $5 \times 10^{17}$ & 0.374 & 0.971 \\
\hline
\end{tabular}


Figure 2 represents the dependence of mobility as a function of electric field using the three expressions.

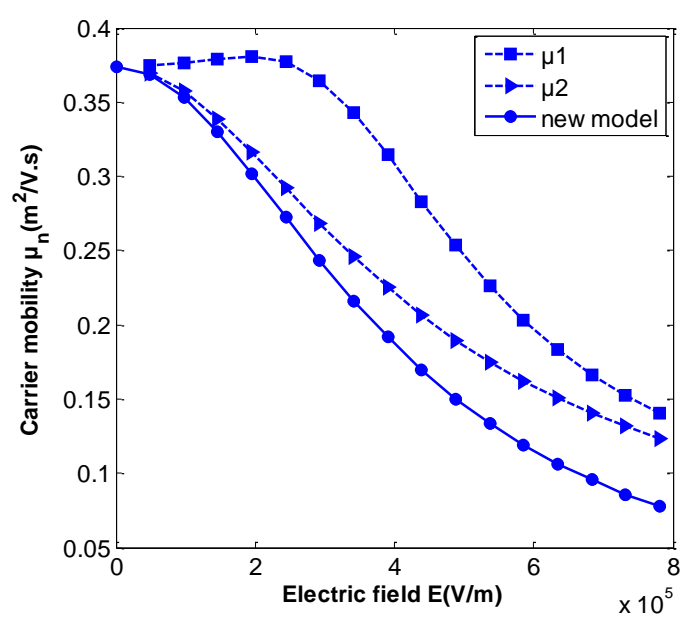

Figure 2. Comparison of the Experimental Results and Theoretical Modeling of Carrier Mobility for Submicron Gaas MESFET's as a Function of the Applied Electric

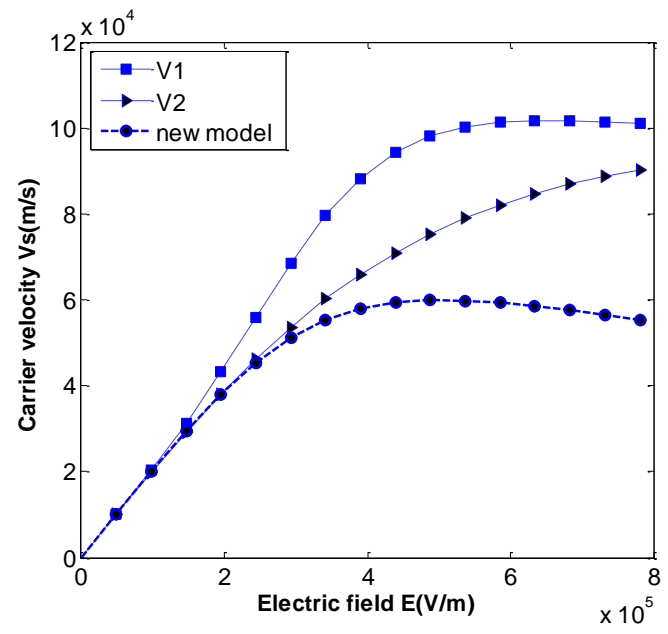

Figure 3. Comparison of the Experimental Results and Theoretical Modeling of Carrier Velocity for Submicron Gaas MESFET's as a Function of the Applied Electric

Figure 4 shows that the simulated drain current using the new model and measured $I-V$ characteristics are in good agreement in different device operation regions, especially the linear and knee regions that are difficult to model. The modeled drain current goes smoothly to zero when $V_{g s}$ approaches pinch-off. The new model also gives an accurate pinch off modeling, as indicated in Figure 5 which shows the comparison of measured and modeled drain current characteristics in pinch off region.

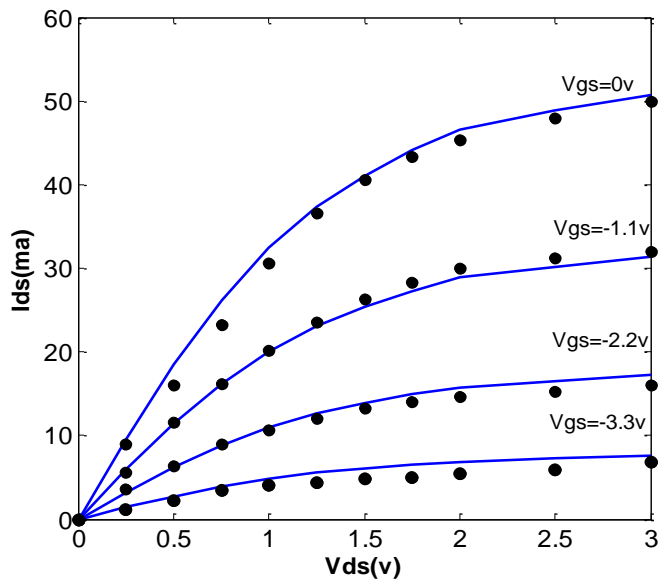

Figure 4. Measured Drain Current Characteristics Ids-Vds of GaAs [dot] and Comparison to Improved

Model with a New Mobility Profile as a Fitting Parameter [Solid Line]

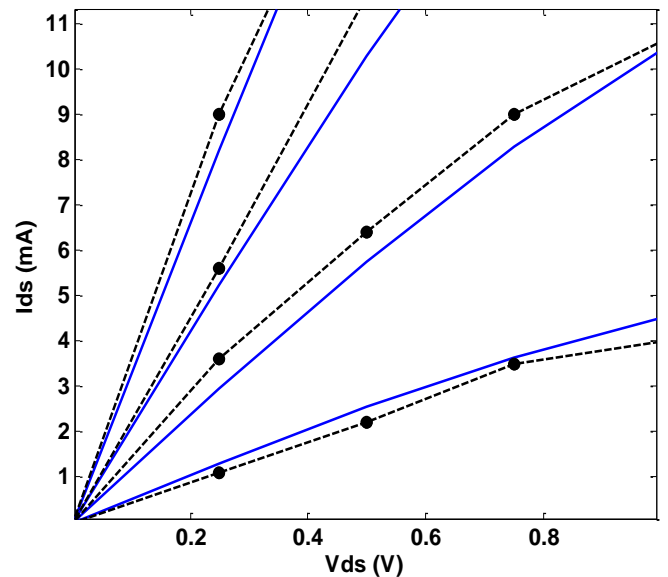

Figure 5. Comparison of measured [dot] and Modeled [Solid Line] Drain Current Characteristics near pinch off Region

The RMS errors of the model are calculated and listed in Table 2. The calculation is made at four bias levels for $V_{g s}$, while $V_{d s}$ changes from $0.5 \mathrm{~V}$ to $3.0 \mathrm{~V}$. Table 2 shows the RMS error is insignificant and greatly reduced near pinchoff condition, the new model produces very accurate fitting result. 


Table 2. RMS Errors of the New Model at different Vgs Values
\begin{tabular}{ccccc}
\hline $\mathrm{V}_{\mathrm{gs}}(\mathrm{V})$ & 0 & -1.1 & -2.2 & -3.3 \\
\hline RMS Error $(\%)$ & 0.977 & 1.658 & 0.337 & 0.196 \\
\hline
\end{tabular}

\section{CONCLUSION}

The GaAs MESFET transistors are attractive devices for the use in microwave applications because of their relatively simple processing and their high-speed and low noise performances [13],[14]. The development and the improvement of new dies of components require new results from modelling, new realisations and new characterisations [15]. In our study we have developed an analytical model to calculate the I-V characteristics of short gate length GaAs MESFET which takes into account the one-dimensional analysis of the charge distribution in the active region and incorporates a field depended electron mobility, velocity saturation and effect of these parameter to the current voltage expressions. The model compares favorably from a submicron GaAs MESFET. More ever, comparisons between the analytical models with different values of mobility proposed shown the effect of mobility it affects directly the output characteristics (I-V) of GaAs MESFET.

The carrier mobility acquires major importance in determining the output characteristics of a GaAs MESFET's. A good fitting of mobility has a great influence on the accuracy of the electrical conductivity and many other physical parameters.

Therefore, we propose a new expression for the mobility-field dependence in GaAs. We show that the results calculated using this model agree well with experimental data. This expression can explain very well the carrier behavior at a wide range of electric field. It can also be implemented easily into computer models describing GaAs devices; in particular, GaAs ion implanted FET's with non-uniform mobility profiles. They also may be used in analytical calculations of the device performance (for example, when an analytical expression for the differential mobility as a function of the field is needed).

\section{ACKNOWLEDGEMENTS} Bouaghi.

The authors gratefully acknowledge the supports from the University of Larbi Ben Mhidi, Oum El

\section{REFERENCES}

[1] H. Mathieu, "Physique des semiconducteurs et des composants électroniques," Edition MASSON, 1990.

[2] C. Azizi, et al., "Le transistor à effet de champ à grille Schottky au GaAs. Analyse et modèle de fonctionnement avec la grille en polarisation directe," Revue de physique appliquée, vol. 16, pp. 303-315, 1983.

[3] T. Gonzalez, et al., "Monte Carlo Analysis of the behavior and special origine of electronic Noise in GaAs MESFET's," IEEE Transaction on electron Device, vol/issue: 42(5), 1995.

[4] C. Karl, "MESFET models basedon GaAs," Colorado state university, 1996.

[5] S. Morarka and S. Mishra, "has 2-D model for the potential distribution and threshold voltage off fully depleted short-Chanel ion-implanted silicon MESFET" S," newspaper off semiconductor technology and science, vol/issue: 5(3), pp. 173-181, 2005.

[6] K. Shin, et al., "Current voltage characteristics off submicrometre GaAs MESFET'S with nonuniform Chanel doping profiles," Solid State Electronics, vol/issue: 35(11), pp. 1639-1644, 1992.

[7] S. Hlo and C. P. Le, "Numerical analysis of the looping effect GaAs MESFET," IEEE Transonelectr Devices, 1992.

[8] S. Bose, et al., "Id-Vd characteristics of optically biased short channel GaAs MESFET," ELSEVIER. Microelectronics Journal, vol. 32, pp. 241-247, 2001.

[9] H. Kiyoyuki, "Importance of Low-Field Drift Velocity Characteristics for HEMT Modeling," IEEE Electron Device Letters, vol/issue: EDL-8(2), 1987.

[10] S. Bouzina, "L'influence des paramètres physiques et géométriques sur les propriétés statiques du transistor MESFET GaAs,” Thèse de magister, Université De Constantine, 2003.

[11] S. Chemise, et al., "Influence of physical and geometrical parameters one electrical properties off short gate GaAs MESFET'," Semiconductor Physics Quantum Electronics and Optoelectronics, vol/issue: 9(2), pp. 34-39, 2006.

[12] N. Matsunagaet, et al., "An improved GaAs model for simulation of analog integrated circuit," IEEE transactions on electron devices, vol/issue: 50(5), 2003.

[13] Y. Saidi, et al., "Effect of mobility on (IV) characteristics of GaAs MESFET," Journal of Electron Devices, vol. 11, pp. 602-608, 2011.

[14] A. Houda and Z. Mourad, "Electromagnetic Modeling of Active Circuit using Wave Concept Iterative Process," Bulletin of Electrical Engineering and Informatics, vol/issue: 5(2), pp. 187 193, 2016.

[15] S. Mellal, et al., "Influence of the two-dimensional analysis on the MESFET transistor characteristics," Journal of Electron Devices, vol. 20, pp. 1724-1728, 2014. 


\section{BIOGRAPHIES OF AUTHORS}

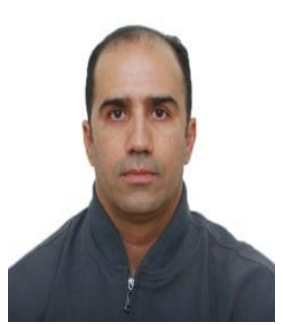

Mounir Azizi was born in Constantine, Algeria on 1977. He received the DEUS (Superior University Study Diploma) from the University of Mentouri, Constantine, Algeria in 2001. And the Magister Degree from the same university on 2005. He is actually preparing the $\mathrm{PhD}$ degree at the university of Larbi Ben Mhidi, Oum El Bouaghi, Algeria. His interests include MESFET's especially GaAs. small-signal modeling of active devices, and microwave and millimeter-wave circuit design.

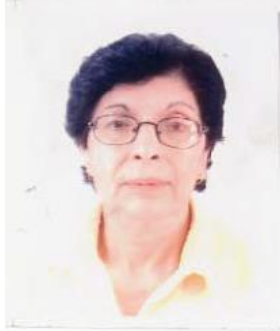

Cherifa Azizi was born in Sigus, Oum El Bouaghi, Algeria, on 1951. He received the License es-science degree in physic from University of Constantine, Algeria in 1973, and the Magister and Doctorate degrees in solid-stat physics Paul Sabatier University, Toulouse, France in 1976 and 1981, respectively. She worked in the Physics Department, University of Constantine, Algeria in 1981 to 2006. She was Head of the physics department, university of Constantine, Algeria from in 1982 - 1986, and she received the professor degree in 1984. Pr Azizi is currently is a Professor and a dean with the Faculty of Sciences, University of Oum El Bouaghi, Algeria. She is research interests include microwave and millimeter-wave measurements, small-signal modeling of active devices, and microwave and millimeter-wave circuit design. 